\title{
ANÁLISIS DE TEXTOS DE LA ASIGNATURA SALUD Y ADOLESCENCIA DE LA ESCUELA SECUNDARIA. ¿ESI DÓNDE ESTÁS QUE NO TE PUEDO ENCONTRAR?
}

ANÁLISE DE TEXTOS DA DISCIPLINA SAÚDE E ADOLESCÊNCIA DA ESCOLA SECUNDÁRIA. ESI ONDE ESTÁS QUE NÃO TE POSSO

\section{ANALYSIS OF TEXTS OF THE HEALTH AND ADOLESCENCE SUBJECT OF THE SECONDARY SCHOOL. ESI WHERE ARE YOU THAT I CAN'T FIND YOU?}

\author{
Claudia Arango \\ Universidad Nacional de Quilmes \\ Silvia Porro \\ Universidad Nacional de Quilmes
}

\section{RESUMEN}

Pensar la cuestión de género, particularmente en el ámbito escolar, permite comprender cómo las personas se engeneran durante toda su vida, a partir de participar en procesos de construcción donde discursos y prácticas sociales institucionalizadas tejen redes de sentido en las que se negocian permanentemente distintas posiciones. Este trabajo pretende dar cuenta del tratamiento que los libros de texto de la asignatura Salud y Adolescencia de la escuela secundaria hacen de la perspectiva de género, y de cómo el lenguaje, la información y fotografías que allí se incluyen contribuyen a la formación de las subjetividades de la juventud a la que van dirigidos. Los textos escolares, en nuestro país, no son sometidos a revisión alguna que contemple la concordancia de los contenidos con la normativa vigente. Los resultados muestran que los textos, en manos del mercado, tienden a reproducir concepciones arcaicas androcéntricas y no contemplan los lineamientos de la ley de Educación Sexual Integral.

Palabras Clave: Género. Textos escolares. Políticas públicas. Redacción androgenerizada.

\section{RESUMO}

Pensar sobre a questão de gênero, particularmente no ambiente escolar, permite entender como as pessoas são engeneradas ao longo de suas vidas, a partir de participar de processos de construção onde discursos e práticas sociais institucionalizados tecem redes de significado nas quais diferentes posições são negociadas permanentemente. Este trabalho tenta dar conta de 


\title{
ANÁLISIS DE TEXTOS DE LA ASIGNATURA SALUD Y ADOLESCENCIA DE LA ESCUELA SECUNDARIA. ¿ESI DÓNDE ESTÁS QUE NO TE PUEDO ENCONTRAR?
}

tratamento que livros didáticos da disciplina Saúde e Adolescência, do ensino médio, fazem da perspectiva de gênero, e como linguagem, informação e fotografias que estão incluídos lá contribuem para a formação das subjetividades dos jovens a que se dirigem. Textos escolares, em nosso país, não estão sujeitos a nenhuma revisão que contemple a concordância do conteúdo com os regulamentos vigentes. Os resultados mostram que os textos, nas mãos do mercado, tendem a reproduzir concepções arcaicas androcêntricas e não contemplam as diretrizes da Lei de Educação Sexual Integral.

Palavras-chave: Gênero. Textos escolares. Políticas públicas. Escrita androgenerizada.

\begin{abstract}
Thinking about the gender issue, particularly in the school environment, allows us to understand how people are engendered throughout their lives, from participating in construction processes where discourses and institutionalized social practices weave networks of meaning in which different positions are permanently negotiated. This work tries to account for the treatment that textbooks of the subject Health and Adolescence, from high school, make from a gender perspective, and how language, information and photographs that are included there contribute to the formation of the subjectivities of the young people to whom they are addressed. School texts, in our country, are not subject to any revision that contemplates the agreement of the content with the current regulations. The results show that the texts in the hands of the market tend to reproduce androcentric archaic concepts and do not include the guidelines of the Integral Sexual Education Law.
\end{abstract}

Keywords: Gender. School texts. Public policy. Androgenerated writing.

\section{Introducción}

Pensar la cuestión de género, particularmente en el ámbito escolar, permite comprender cómo las personas se engeneran durante toda su vida, a partir de participar en procesos de construcción donde discursos y prácticas sociales institucionalizadas tejen redes de sentido en las que se negocian permanentemente distintas posiciones. Es así como el concepto de reglamento de género se materializa y la educación escolar, con sus prácticas sociales, contribuye a la formación del género a través de la propia regulación que la institución proporciona. Es Judith Butler la que menciona cómo la norma reglamentada "opera dentro de las prácticas sociales como el estándar implícito en la normalización” (BUTLER, 2012a) y es así como niños y niñas, dentro de la institución escolar, se forman y (re)forman en ese complejo entramado reglamentado.

La formación individual se elabora en el primer círculo de socialización, la familia, que inculca en niños y niñas los valores y normas de la sociedad y, conjuntamente, conduce a interiorizar los estereotipos de género. Dentro del segundo círculo se encuentran la Escuela y el ámbito social y cultural donde todo está inmerso. 


\section{ANÁLISIS DE TEXTOS DE LA ASIGNATURA SALUD Y ADOLESCENCIA DE LA ESCUELA SECUNDARIA. ¿ESI DÓNDE ESTÁS QUE NO TE PUEDO ENCONTRAR?}

\section{Punto de partida}

El tema de la presente investigación pretende ser un aporte a la comprensión de la transformación continua de las subjetividades del alumnado en el ámbito escolar. Esta investigación anhela convertirse en disparador de discusión en las mesas de diseño de políticas públicas, con el objetivo de que se incluya en los diseños curriculares y documentos oficiales, estrategias y contenidos necesarios que permitan al cuerpo docente visibilizar, a través de una mirada analítica y reflexiva, cuántas y cuáles son las huellas que dejan a diario, las actividades áulicas, en sus estudiantes.

Asimismo, se espera aportar hacia la necesidad de que las autoridades responsables de la aprobación de los textos escolares realicen una revisión, en clave de Educación Sexual Integral, de todos los materiales que se aprueban para ser utilizados por el estudiantado en todas las asignaturas de la educación pública de todos los niveles.

\section{Sexo natural y género construido}

El término género es oriundo de países de habla inglesa y comenzó a circular con mucha frecuencia hacia fines de los años 80 en nuestro país, como influencia tardía de los debates españoles denominados igualdad vs diferencia que se dieron a principios de la citada década en la península Ibérica. Como afirma Laudano (2006, p. 149), "la perspectiva de género se perfilaba como más aceptable; sobre todo si no avanzaba en definir las relaciones entre los sexos como atravesadas por instancias de poder desiguales". Por esos tiempos el sexo era visto como lo biológico, lo natural y por la tanto inmutable; y el género como construcción histórico social, lógicamente cambiable, facilitando la crítica cultural del momento.

El sexo como categoría en sí misma fue desde el comienzo ese "ideal regulatorio" (FOUCAULT, 2012:12) manifestándose como normativa y como práctica reguladora. Es esa fuerza reguladora la que le confiere el poder de producir los cuerpos que controla.

La antropóloga estadounidense Margaret Mead introduce fuertemente en su investigación la idea de deconstruir el determinismo biológico. Los roles sociales "no están determinados por el sexo biológico sino construidos por la Sociedad, variando entre distintas sociedades y épocas” (MARTIN CASARES, 2006, p. 72). 


\section{ANÁLISIS DE TEXTOS DE LA ASIGNATURA SALUD Y ADOLESCENCIA DE LA ESCUELA SECUNDARIA. ¿ESI DÓNDE ESTÁS QUE NO TE PUEDO ENCONTRAR?}

En palabras de Butler (2012b, p.18) "el sexo es una construcción ideal que se materializa obligatoriamente a través del tiempo". Este proceso de construcción se da de manera lenta y constante en cada micropráctica diaria a partir de la repetición rutinaria y forzada de las normas. Pero el hecho de que esas normas tengan que ser reiteradas da sobradas muestras de que los cuerpos nunca acatan al pie de la letra lo que se les impone o sea que esa materialización nunca se da como copia idéntica completa, sino que se resignifican permanentemente dichas repeticiones.

Ahora, ante la pregunta acerca de ¿cómo es que se relaciona la idea de materialización de las normas con la performatividad del género? La respuesta no tarda en llegar y viene de la mano de Judith Butler (BUTLER 2012b, p. 272):

La performatividad debe comprenderse como la práctica reiterada y referencial en la cual el discurso produce los efectos que nombra. Entender la performatividad como una decisión voluntaria y arbitraria implicaría pasar por alto la historicidad del discurso y en particular, la historicidad de las normas (las cadenas de iteración invocada y disimuladas en la enunciación imperativa) constituyen el poder que tiene el discurso de hacer realidad lo que nombra.

\section{Identidad en construcción}

Puede empezar a hablarse del proceso de construcción de la identidad desde antes del momento del nacimiento, Graciela Morgade esgrime un concepto interesante que lleva a reflexionar que cuando se piensa a un sujeto es imposible omitir, en ese ejercicio de pensamiento, su condición de mujer o varón y esto sucede en el seno familiar, desde antes de la existencia material de las personas (MORGADE, 2001, p. 35), continuando luego este proceso de formación de la identidad en la infancia y adolescencia, período donde el espacio escolar se constituye como el sustrato de las rutinas diarias del estudiantado.

Palabras como sexualidad e identidad no marcan la posesión de ciertas características o rasgos sino más bien indican la manera con la que se relacionan las personas entre sí. En palabras de Butler "el otro adquiere una dimensión sexuada, un lugar fundamental a partir del cual se construye la propia identidad" (BUTLER, 2012a).

Entonces, de qué manera puede pensarse la construcción del género de cada persona. Para intentar responder el interrogante planteado es indispensable recurrir al concepto de 


\section{ANÁLISIS DE TEXTOS DE LA ASIGNATURA SALUD Y ADOLESCENCIA DE LA ESCUELA SECUNDARIA. ¿ESI DÓNDE ESTÁS QUE NO TE PUEDO ENCONTRAR?}

reglamento de género y, que explica cómo la educación escolar a partir de sus prácticas sociales reglamentadas contribuye a la formación del género a través de la propia regulación que la institución proporciona.

En esta línea Gloria Bonder (1998) nos invita a pensar que toda construcción histórica implica un atravesamiento discursivo en el que se ponen en juego las luchas de poder e intereses manifiestos en una sociedad.

\section{Identidad y Lenguaje}

La palabra es una creación propiamente humana, se necesita del lenguaje para existir y es el lenguaje en sí mismo el que interviene y vehiculiza la formación de la identidad. Desde el comienzo mismo es el nombre el que nos permite cierta existencia social.

Como parte de la humanidad y desde el mismo momento de la llegada a este mundo los seres son atravesados por diversos discursos, primero serán las palabras del grupo primario las que comenzarán el proceso de modelación y luego, en unos casos más pronto que en otros, serán los discursos escolares a manos de docentes y materiales, los que imprimirán su marca en las infancias dentro de las instituciones educativas.

El lenguaje ejerce su fuerza, aun cuando el discurso intenta contrarrestarlo. Judith Butler afirma que "estamos formados por el lenguaje, entonces este poder constitutivo precede y condiciona cualquier decisión que pudiéramos tomar sobre él, insultándonos desde su poder previo" (BUTLER, 1997, p. 16).

Pero esa construcción no es unilateral, no debe pensarse una concepción determinista que lleve a sostener que el discurso forma de manera unívoca a las personas...’la construcción no es un acto único ni un proceso causal iniciado por un sujeto y que culmina en una serie de efectos fijados" (BUTLER, 2012b, p.29).

Ese proceso temporal denominado "construcción” funciona a partir de la reiteración de normas, pero esta repetición no se produce de manera idéntica sino que se da como un proceso de sedimentación inestable dando lugar a las posibilidades de deconstrucción o resistencia. 


\section{ANÁLISIS DE TEXTOS DE LA ASIGNATURA SALUD Y ADOLESCENCIA DE LA ESCUELA SECUNDARIA. ¿ESI DÓNDE ESTÁS QUE NO TE PUEDO ENCONTRAR?}

\section{Identidad Discurso e Institución Escolar}

La escuela fue creada para ocuparse de los asuntos públicos, por esto la sexualidad, si bien siempre presente, no fue contemplada por el discurso oficial que la confinó a la esfera de lo privado y como tal debía permanecer oculta. Michael Foucault a lo largo de su obra La Historia de las Sexualidades hace referencia a que desde la época victoriana la sexualidad se convirtió en un "discurso omnipresente de represión” ayudado por el deliberado interés en eliminar todo lo relativo al sexo, como si eso fuera suficiente para dejarlo encerrado en la órbita privada (MORGADE, 2011, p.10).

En las sociedades modernas el orden está garantizado por las instituciones sociales que han surgido luego de largos procesos de convencionalización de las prácticas sociales que estructuran la vida cotidiana (GIDDENS, 1994). Son las instituciones las que orientan el modo en que los individuos viven la cotidianidad. Las personas de una sociedad participan, desde diversos roles y perspectivas, en la reproducción y transformación de las instituciones y también ejercen acciones de resistencia a las mismas. El concepto de resistencia, como contradicción interna, supone superar la visión pesimista y apocalíptica de la reproducción irremediable (PASSERON, 1983). Es Pierre Bourdieu quien plantea la existencia de diferentes estrategias de reproducción que no pueden definirse acabadamente si no es en relación con mecanismos de reproducción, institucionalizados (BOURDIEU, 2011).

Es dentro de las instituciones donde se produce la construcción de la "voz propia" proceso que se desarrolla conjuntamente con la configuración de la identidad cultural. En dichos de Fraser "las esferas públicas no son sólo espacios para la formación de la opinión discursiva; son también espacios para la formación y la concreción de las identidades sociales" (Fraser citado en MORGADE, 2011).

\section{Discurso Oficial. Políticas Públicas}

El Estado, por su parte, cumple un papel importante en la producción y reproducción del orden de género dominante, a través de la formulación y ejecución de políticas públicas, sean éstas de familia, escolares, laborales y de seguridad social, entre otras.

En cuanto a los textos escolares se ve un claro alejamiento y desinterés del Estado que no prevé ninguna regulación para los materiales que las editoriales lanzan al mercado. Los 


\section{ANÁLISIS DE TEXTOS DE LA ASIGNATURA SALUD Y ADOLESCENCIA DE LA ESCUELA SECUNDARIA. ¿ESI DÓNDE ESTÁS QUE NO TE PUEDO ENCONTRAR?}

grupos editoriales sólo se ocupan de incluir en los textos, los temas que figuran en los diseños curriculares. Históricamente, al no verse diferenciadas las experiencias y necesidades de hombres y mujeres, los Estados diseñaban sus políticas tomando como patrón los intereses y las demandas de los hombres.

Con la sanción de ley 1420 primera ley de educación, en 1884 el Estado buscó regular por medio de disposiciones detalladas todo lo que sucedía en las escuelas para alcanzar el ideal homogenizador de la época. En relación a los libros de texto La ley 1420 en el inc.15 del art. 57 dejaba bien claro que la normativa pretendía: «prescribir y adoptar los libros de texto más adecuados para las escuelas públicas, favoreciendo su edición y mejora por medio de concursos u otros estímulos y asegurando su adopción uniforme y permanente a precios módicos ». Para poder dar curso a este requerimiento el Estado creó, en 1884, una Comisión Didáctica, conformada por prestigiosos miembros de la corporación de educadores. Con diferentes idas y venidas sobre la inclusión y exclusión de determinados tópicos y criterios los textos permanecieron bajo la regulación estatal hasta mediados del siglo XX, cuando en la Argentina se recupera la democracia, dando por terminado el período gobernado por dictaduras militares. El nuevo gobierno democrático desreguló el control de los libros de texto "aludiendo a que mantener los planes de aprobación por parte del Estado representaba una continuidad propia de los regímenes autoritarios o totalitarios y que actuaban en contra de la libertad del maestro y del desarrollo del libro de texto" (Narodowsky y Manolakis, 2001). Los textos escolares pasaron de esta manera a estar en manos del mercado perdiendo el Estado la responsabilidad por los contenidos.

\section{Ley 26150 Programa Nacional de Educación Sexual integral}

Comprender las lógicas con las que se diseñan los textos prescriptivos resulta una tarea fundamental y necesaria para poder discernir qué mensaje se encuentra encerrado en las palabras escritas de los discursos oficiales. Decodificar esos mensajes nos acerca a la interpretación de las leyes y los Documentos Curriculares, teniendo en cuenta que los mensajes se encuentran ocultos entre las palabras escritas y también en aquellas que se acallan.

Entre los intentos de inclusión, el sistema educativo de Argentina ha promulgado la Ley $N^{\circ}$ 26.150 Programa Nacional de Educación Sexual Integral, que establece, en su art. $1^{\text {o }}$ "que todos los educandos tienen derecho a recibir educación sexual integral en los establecimientos 


\section{ANÁLISIS DE TEXTOS DE LA ASIGNATURA SALUD Y ADOLESCENCIA DE LA ESCUELA SECUNDARIA. ¿ESI DÓNDE ESTÁS QUE NO TE PUEDO ENCONTRAR?}

educativos públicos sean de gestión estatal o privada de las jurisdicciones nacional, provincial, Ciudad Autónoma de Buenos Aires y municipal”. Desde el comienzo se observa que el uso de la palabra "educandos" en la forma gramatical masculina contribuye a perpetuar la tradicional visión androcéntrica que debería desarticular.

Uno de los objetivos de esta ley nacional manifiesta que es hay que "Procurar igualdad de trato y oportunidades para varones y mujeres". Resulta alarmante, y hasta contradictorio, con lo que se expresa desde el propio título de la ley que uno de sus objetivos reduzca la igualdad de trato y oportunidades a una cuestión binaria restrictiva entre varones y mujeres inhabilitando pensar, desde una clara lógica hegemónica reguladora, en la inclusión de otros colectivos (BUTLER, 2006).

Otro aspecto a tener en cuenta es que, a lo largo de la redacción de la citada normativa nacional, la palabra GÉNERO no figura entre la letra escrita, dejando a trasluz la NO intención de incluir el tratamiento y reflexión de la perspectiva de género en el ámbito educativo.

\section{Ley 14744 ESI de la Provincia de Buenos Aires}

Esta ley fue sancionada el 4 de junio de 2015. Se recuerda que la Ley Nacional de Educación Sexual Integral N 26150 sancionada el 4 de octubre de 2006, en su artículo $10^{\circ}$, establecía que cada jurisdicción tenía "un plazo de ciento ochenta (180) días para establecer un plan que permita el cumplimiento de la presente ley, a partir de su vigencia y en un plazo máximo de cuatro (4) años". La Dirección General de Escuelas de la Provincia de Buenos Aires se tomó 8 años y 8 meses en sancionar la ley provincial, más del doble del tiempo máximo establecido, de esto se desprende cuál era el interés real del tratamiento de la educación sexual integral desde las autoridades educativas provinciales.

En el artículo $3^{\circ}$ se define a la Educación Sexual integral como el "conjunto de actividades pedagógicas que articulan aspectos biológicos, psicológicos, sociales, afectivos y éticos, destinados a brindar contenidos tendientes a satisfacer las necesidades de desarrollo integral de las personas y la difusión y cumplimiento de los derechos sexuales y reproductivos definidos como inalienables, inviolables e insustituibles de la condición humana". Esta normativa, al hablar de actividades pedagógicas le confiere la responsabilidad central al cuerpo docente.

Revista RBBA $\mid$ Revista Binacional Brasil Argentina 
ANÁLISIS DE TEXTOS DE LA ASIGNATURA SALUD Y ADOLESCENCIA DE LA ESCUELA SECUNDARIA. ¿ESI DÓNDE ESTÁS QUE NO TE PUEDO ENCONTRAR?

Como si fuera necesario incluir en cada documento una muestra de incoherencia, en el $4^{\circ}$ artículo se incluye el término "educandos", escrito gramaticalmente en masculino.

$\mathrm{El} 5^{\circ}$ de los artículos de la ley incluye un extenso detalle de las funciones, y se incluye la perspectiva de género, el respeto por la diversidad, la no discriminación y contempla al placer sexual como derecho, lo que no se había visto en las otras normativas. Incluye el derecho a la procreación responsable, al conocimiento de métodos anticonceptivos para prevenir el embarazo no deseado y a la morbimortalidad materna. En la interpretación de esta última subyace como convidado de piedra el aborto séptico, que practicado clandestinamente se lleva cientos de víctimas al año.

Si bien uno de los objetivos propone diseñar, producir o seleccionar los materiales didácticos, a cuatro años de la redacción de la ley continúan llegando a las escuelas los materiales elaborados por el Ministerios de Educación de la Nación en 2012 y los libros de textos continúan sin control en manos del mercado.

\section{Cuestiones Metodológicas}

Este trabajo se orienta a identificar e interpretar la realidad escolar, como espacio de formación y transformación de identidades del estudiantado entre la materialización del curriculum, y los sistemas de mensajes que se ponen en juego en la letra escrita de los textos escolares y las interpretaciones del cuerpo docente. Se busca, desde una interpretación holística, comprender en profundidad cómo el significado que la palabra escrita contiene, impacta en la formación de la identidad del estudiantado, si el cuerpo docente no identifica la intención que subyace en los textos que ofrecen a su alumnado.

Al tomar la realidad educativa (Mc MILLAN y SCHUMACHER, 2005) como objeto de estudio se la reconoce como una dimensión subjetiva en la que los miembros intervinientes co-construyen la realidad cotidiana reactualizándola permanentemente, atribuyéndole a dicha interacción, el carácter simbólico que vehiculiza la atribución de significados por parte de las personas. Para reflejar con claridad lo antedicho, se incluyen palabras de Pérez Gómez (1994, p.120): "los seres humanos son animales suspendidos en redes de significados que, en gran medida, han contribuido a tejer".

También resultan pertinentes para fundamentar los resultados los aportes del interaccionismo simbólico (DEUTSCH y KRAUSS, 1969; AGUADO TERRÓN, 2004) que Revista RBBA $\mid$ Revista Binacional Brasil Argentina 


\section{ANÁLISIS DE TEXTOS DE LA ASIGNATURA SALUD Y ADOLESCENCIA DE LA ESCUELA SECUNDARIA. ¿ESI DÓNDE ESTÁS QUE NO TE PUEDO ENCONTRAR?}

brinda las herramientas para interpretar cómo las personas se sirven de los significados para actuar en lo cotidiano.

Es Serge Moscovici quien sostiene que la representación social es una modalidad particular del conocimiento, cuya función es la elaboración de los comportamientos y la comunicación entre los individuos (Moscovici, 1961). Los procesos de comunicación, sean estos escritos u orales, resultan un rico material para visibilizar el juego interno entre la interpretación y la comunicación misma. En este escrito se hace foco sobre los discursos escritos en textos escolares de la asignatura salud y adolescencia que involucran a docentes y estudiantes en torno a la vida en las aulas.

La selección de prácticas discursivas comprendidas en los textos escolares se constituye en unidades de análisis, reflexión y evaluación de la dinámica escolar, interpretada ésta, como uno de los factores que contribuyen a la transformación de las identidades del estudiantado.

\section{Análisis del texto escolar de la Materia Salud y Adolescencia}

En este trabajo se presenta el análisis de un solo texto de la asignatura Salud y Adolescencia, asimismo en la tesis completa, de la que el presente escrito es una pequeña parte se analizan los cuatro textos más vendidos del mercado.

El libro presenta una unidad titulada "Hablemos de adolescencia", el apartado comienza haciendo alusión a si existe una o más adolescencias, en todo momento se hace referencia a los adolescentes, utilizando el artículo en masculino. El texto se encuentra acompañado por imágenes, la primera es la fotografía de la escultura griega Discóbolo ${ }^{i}$ que muestra a un atleta varón instantes antes del lanzamiento del disco, esta imagen se acompaña con un epígrafe que hace referencia a que en la escultura se "muestra la belleza y fortaleza física juvenil" como si estas características fueran privativas de los varones.

El capítulo culmina con una serie de tareas denominadas "Actividades finales", este apartado incluye dieciocho actividades. Y en todas ellas se hace referencia a la adolescencia, a la adultez y a la juventud con el artículo masculino los, precediendo al sustantivo, reforzando a cada momento el androcentrismo manifiesto con el que el equipo que escribió este texto, pensó y plasmó el material que se ofrece en la materia Salud y Adolescencia y con el que nuestros y nuestras jóvenes forjan sus identidades dentro del espacio escolar. 


\section{ANÁLISIS DE TEXTOS DE LA ASIGNATURA SALUD Y ADOLESCENCIA DE LA ESCUELA SECUNDARIA. ¿ESI DÓNDE ESTÁS QUE NO TE PUEDO ENCONTRAR?}

Asimismo, en la actividad número 11 se pide "Describí los cambios corporales que comienzan a darse en la entrada a la adolescencia, teniendo en cuenta diferencias y similitudes entre ambos géneros". En esta actividad se confunde el sexo con el género invisibilizando la posibilidad de presentar y pensar al género como una construcción social y no como un atributo asociado al sexo natural con el que nacemos.

Cuando se trata el tema de la identidad, la presenta como estable pero dinámica, esto es porque cambiamos a través del tiempo y bajo el título "Quienes somos en la escuela" el texto propone que: "el ingreso a la secundaria requiere de un mayor grado de responsabilidad y las tareas se vuelven más exigentes para chicos y chicas, la escuela tiene un papel fundamental, sobre todo porque brinda la primera etapa de la preparación para los trabajos que los chicos y las chicas van a desempeñar en el mundo adulto".

Si bien en este párrafo se habla de ambos sexos, en el renglón siguiente dice que "la escuela media tiene como misión formar a los chicos para ser ciudadanos responsables y ocupar lugares valiosos en la sociedad. El acceso al conocimiento, el aprendizaje de las formas de trabajar y la adquisición de valores que facilita la escuela son elementos básicos de la identidad como personas; son las bases de los adultos que serán en los próximos años en el ámbito en que elijan desempeñarse".

A continuación, otro título, propone conocer sobre "Motivos de la consulta médica" y dice que "las mujeres consultan frecuentemente por los temas relacionados con la sexualidad. En cambio, los varones no suelen hablar de este tema con los profesionales, muchas veces no saben dónde ir si tienen dudas y otras veces creen que esto no es motivo para consultar", si luego de esta frase el o la docente a cargo no promueve la reflexión o el texto no incluye un párrafo donde diga que es importante la consulta con profesionales de la salud, independientemente del sexo de las personas, parece que esta manera de actuar fuera la esperada para los varones adolescentes.

Otro de los apartados trata sobre el Enfoque de Género donde desde el mismo texto, se aclara que "existen inequidades innecesarias, evitables e injustas entre hombres y mujeres (...) el enfoque de género es el que facilita la comprensión y el abordaje de estas inequidades". Es evidente que ninguno de los nueve integrantes del equipo que participó de la escritura de este libro, del cual llamativa y alarmantemente ocho son mujeres, considera que los lenguajes tanto orales como escritos son performativos y por ende no reflexionan sobre el poder performador de sus propios escritos. 


\section{ANÁLISIS DE TEXTOS DE LA ASIGNATURA SALUD Y ADOLESCENCIA DE LA ESCUELA SECUNDARIA. ¿ESI DÓNDE ESTÁS QUE NO TE PUEDO ENCONTRAR?}

Más adelante y bajo el título "El Aspecto corporal" se hace referencia a la importancia de que la adolescencia tengan "una autoimagen positiva de sí misma ya que sentirse conforme consigo misma y atractiva para los otros fundamental para el desarrollo de la autonomía".

Luego menciona que en el caso de que la adolescencia exprese disgusto con su aspecto corporal, son "los profesionales los que deben diferenciar normalidad de enfermedad". La inclusión del término normalidad en este párrafo preocupa, ya que en lugar de hablar sobre características saludables se hace referencia a una imagen normalizada de la adolescencia, de esto se desprende que el equipo de escritores comparte un concepto de imagen corporal normal, de la adolescencia claramente estereotipada, y todo aquello que no se ajuste a esa imagen es considerado anormal y asociado al concepto de enfermedad.

La unidad denominada Salud, alimentación y modelo estético hegemónico, comienza haciendo referencia a la alimentación como fenómeno complejo en el que inciden la dimensión biológica, emocional, sociocultural, económica y política. En las imágenes que se incluyen para acompañar el tema de alimentación se ve a una adolescente claramente apesadumbrada comiendo una barra de chocolate, esta imagen refuerza el estereotipo de que la angustia femenina se quita con la ingesta compulsiva de dulces y helado, también se incluye una foto de una mujer amantando y la de un hombre, de saco y corbata, escribiendo sentado al escritorio, consolidando el estereotipo de mujer madre y hombre de trabajo.

Más adelante bajo el título Publicidad y consumo se hace referencia a que el proceso de globalización y las publicidades hacen que los medios de comunicación ejerzan su influencia sobre los gustos de los adolescentes y promueven el ideal de belleza que se sostiene hoy en día; mujeres muy delgadas y con curvas y varones fuertes y atléticos, cuerpo que se presentan como los indispensables para alcanzar el éxito y la aceptación, estas afirmaciones deberían estar seguidas por una sólida y contundente fundamentación que desestime y desaliente la persecución, por parte de la adolescencia, de ese ideal de belleza que sólo contribuye a deteriorar la autopercepción que los y las adolescentes tienen de su propia imagen corporal y de sus pares. Ideal que muchas veces se constituye en un riesgo para su salud, en algunos casos llegando a comprometer sus vidas.

Otro de los títulos de esta unidad se ocupa de los estereotipos de belleza, este apartado comienza definiendo estereotipo como el "conjunto de características, muchas veces alejadas de la realidad o bien prejuiciosas, que se instalan como las adecuadas o correctas" y continúa aclarando que "en este caso para ser bello o bella se deben poseer las características que marca 


\section{ANÁLISIS DE TEXTOS DE LA ASIGNATURA SALUD Y ADOLESCENCIA DE LA ESCUELA SECUNDARIA. ¿ESI DÓNDE ESTÁS QUE NO TE PUEDO ENCONTRAR?}

el estereotipo de belleza masculina o femenina (...) y estos estereotipos se asocian con el éxito y la riqueza", nuevamente aparece la matriz binaria como si la belleza fuera un característica derivada del género, femenino-masculino, y no una interpretación subjetiva de hombres y mujeres.

Luego, el título El modelo estético hegemónico, inicia de la siguiente manera: el modelo estético que predomina, el que representa el cuerpo y la apariencia que todos quisieran tener es el que coincide con las características físicas que prefieren las personas de los sectores mejor posicionados en la sociedad. Nuevamente, en este fragmento se refuerzan los estereotipos ya que la frase que está subrayada y que en el texto original aparece entre comillas, no solo no invita a reflexionar sobre la construcción social de los estereotipos, ni el concepto de hegemonía; sino que relaciona directamente a la gente de los sectores mejor posicionados como poseedora de las características corporales en que se sustenta dicho bienestar, desestimando el esfuerzo, la capacidad intelectual y el estudio. Inmediatamente surge la pregunta, ¿cuál será la interpretación que el equipo escritor hace sobre quiénes pertenecen y cómo accedieron a ser personas que integran los sectores mejor posicionados? Lamentablemente, esta investigación no puede más que inferir o sospechar la respuesta.

En párrafos siguientes se menciona a la globalización y a los medios masivos de comunicación como los causantes de extender por el mundo los ideales de belleza y éxito, como si ambos fueran agentes en sí mismo, independientemente de las personas que los componen, impidiendo de esta manera que el público lector adolescente se constituya como agente de reflexión, comprensión y cambio. En palabras de la antropóloga Rita Segato (2017):

Hay una mirada que corregir, la de los errores instalados en la sociedad reforzados en los estereotipos. Es necesario hacer un trabajo de corrección de los desvíos de compresión originados en una historia de opresión y desigualdad. Contrariamente, los medios (ni el texto en análisis) ${ }^{\mathrm{ii}}$ no realizan ese trabajo, sino que refuerzan prejuicios presentes que son del ámbito de la mirada de la sociedad sobre las personas ${ }^{\mathrm{iii}}$.

Dentro de la misma página del texto figura un apartado que se corresponde con el título “Para acerare al modelo... ¿cirugías?”, en él se comienza presentando a las cirugías estéticas como una parte de la ciencia médica que centra su atención en cuestiones de aspecto y belleza y que de esta manera las personas pueden resolver sus conflictos, sus insatisfacciones y elevar la autoestima, no haciendo mención de las cirugías reparadoras. Nuevamente se responsabiliza a la televisión y a las publicidades, como si éstas no fueran productos humanos intencionados 


\section{ANÁLISIS DE TEXTOS DE LA ASIGNATURA SALUD Y ADOLESCENCIA DE LA ESCUELA SECUNDARIA. ¿ESI DÓNDE ESTÁS QUE NO TE PUEDO ENCONTRAR?}

y con finalidad económica. Si bien se incluye que este tipo de práctica "plantea riesgos" también aclara que son como toda otra operación. A continuación, se ve una imagen de una prótesis mamaria con un moño y con el siguiente título La primera, te la regalo, en este apartado se menciona que antes, "hace mucho tiempo, para los cumpleaños de 15 o 18 años si se quería hacer un regalo valioso se obsequiaba un anillo de oro u otra joya, luego vino la época de los autos, las computadoras de última generación, el viaje (...) ahora se está registrando una tendencia que se está imponiendo como moda entre los sectores más pudientes: regalar cirugías". Luego hace mención a que las cirugías "a las que se someten los adolescentes son las de nariz, orejas, liposucción, reducción o aumento de los senos y aplicación de colágeno en los labios", y como si eso no fuera suficiente para interpretar lo anterior como apología de las cirugías estéticas en adolescentes, una última oración dice: "Un dato interesante es que, en su mayoría, son mujeres quienes acuden a las consultas con médicos cirujanos para reformar su cuerpo", aquí el cuerpo de la mujer es presentado como una cosa a modificar y, si bien el equipo escritor no aclara por qué le parece interesante que las mujeres sean quienes concurren a realizarse cirugías, queda claro que son los médicos varones quienes las realizan como si fueran escultores frente a su obra. Nuevamente, resulta oportuno y necesario incluir palabras de la autora anteriormente citada "La Pedagogía de la crueldad es aquello que induce a transformar a las personas en cosas. Enseña a mirar el cuerpo humano como cosa, es la cosificación de la vida" (SEGATO, 2017) ${ }^{\text {iv }}$.

En la cuarta sección del libro se introduce el tema de la Educación Sexual Integral. Desde la primera página un recuadro anticipa qué temas se tratarán en el capítulo, y de los cinco que plantea, cuatro se refieren a los derechos sexuales y reproductivos, reduciendo la tan pretendida integralidad a la reproducción. Es importante destacar que la salud sexual va mucho más allá de lo reproductivo y que también comprende la identidad, lo que queremos y sentimos, las relaciones interpersonales, y estos aspectos forman parte nuestra durante toda la vida y no solo en el momento de la reproducción (UNESCO, 2014).

A continuación en el texto aparece el título Géneros y estereotipos y comienza con la definición extraída de un diccionario del que no consta su referencia que dice que "el género se define como el conjunto de individuos o de objetos que tienen características comunes" y agrega que al referirse a los seres humanos "el género se asocia al sexo y a la sexualidad" y agrega que el género o rol sexual ${ }^{v}$ es el significado que una sociedad le asigna al hecho de ser varón o mujer. Según esa manera de concebir la masculinidad y la feminidad, cada sociedad le asigna 


\section{ANÁLISIS DE TEXTOS DE LA ASIGNATURA SALUD Y ADOLESCENCIA DE LA ESCUELA SECUNDARIA. ¿ESI DÓNDE ESTÁS QUE NO TE PUEDO ENCONTRAR?}

distintos roles a mujeres y varones. Según su género se espera que las personas sientan y actúen de una determinada manera.

Esta definición de género lo acota al binarismo tradicional donde se espera que los varones actúen de manera masculina y las mujeres sean femeninas y que la sociedad, a su vez, también estaría esperado que actúen de una determinada manera. Luego dice que la tradición cultural occidental espera que los hombres sean valientes, seguros, independientes, protectores, racionales, fuertes, líderes, trabajadores y que ejerzan la autoridad. En cambio, que las mujeres sean débiles, sumisas, indecisas, conversadoras, que se emocionen con facilidad y expresen sus sentimientos y que tengan una actitud maternal. Se hubiera esperado que luego de semejante declaración sesgada, cargada del más duro patriarcado tradicional, se acompañara de un párrafo que apuntara a la desarticulación de estereotipo binario de hombre rudo y racional; y mujer débil, sumisa y dependiente. Al no aparecer ningún comentario contrario se refuerza la concepción androcéntrica, que en ningún momento se aprecia que quisiera ser cuestionada

Mientras estas ideas sigan en los textos escolares como afirmaciones, la reproducción del patriarcado dominante habrá encontrado una nueva forma de perpetuarse oculta detrás de una aparente educación sexual integral dentro de las escuelas.

El apartado siguiente plantea el tratamiento de la sexualidad y la reproducción y con ese mismo título comienza. En primera instancia aborda los caracteres sexuales con graves errores que entran dentro de la categoría redacción androgenerizada ${ }^{v i}$ que se introyecta en los cuerpos escolares institucionalizados.

El capítulo comienza con un grosero error al definir el sexo, y dice: en el capítulo anterior dijimos que el sexo es una condición biológica por la que se distingue entre individuos masculinos y femeninos, a continuación, sigue definiendo a los testículos y los ovarios como las gónadas masculinas y femeninas respectivamente, he aquí otro ejemplo no solo de concepto erróneo sino de redacción androgenerizada que invade al texto. En su lugar debería decir que los testículos son las gónadas presentes en los varones y los ovarios órganos de las mujeres. Esta confusión entre género y sexo se repite a la hora de citar los caracteres sexuales secundarios. También se nombran los andrógenos, como las hormonas sexuales masculinas en lugar de decir que son las hormonas presentes en los varones y en el caso de las mujeres nombra a los estrógenos y la progesterona como las hormonas sexuales femeninas en lugar de decir que son las hormonas segregadas por glándulas que se encuentran en el cuerpo de las mujeres. 


\section{ANÁLISIS DE TEXTOS DE LA ASIGNATURA SALUD Y ADOLESCENCIA DE LA ESCUELA SECUNDARIA. ¿ESI DÓNDE ESTÁS QUE NO TE PUEDO ENCONTRAR?}

Otra clara presencia de redacción androgenerizadabien visible se evidencia en varios títulos, como ser: sistema reproductor masculino y sistema reproductor femenino, nuevamente enfrentando al público lector a un error conceptual en el que se confunde sexo y género.

A vuelta de página se incluye el tema de la planificación familiar. Entre los párrafos destaca una imagen en la que se ve a una mujer en la consulta con un médico varón. Si bien se presenta la anticoncepción y el control de la natalidad como temas que deben ser tratados respetando opiniones y estableciendo acuerdos en la pareja, la inclusión de esa imagen ofrece otro mensaje donde se traduce que la planificación familiar parecería depender de la mujer y de la charla que ella pudiera tener con la persona profesional de la salud que la asiste, que en este libro de textos resulta que siempre está representada por profesionales varones.

La información sobre la anticoncepción incluye los métodos naturales donde la mujer toma el rol protagónico, ya que se le pide conocer muy bien su cuerpo y también se ofrece información para que ella calcule su período fértil, identificando ciertas características del flujo vaginal y la temperatura basal, momento en el que se aconseja abstinencia sexual. Eso sí no ofrece ninguna aclaración de lo poca efectividad del método.

Cuando se abordan los métodos anticonceptivos no naturales se incluyen los anticonceptivos hormonales, los espermicidas, los dispositivos intrauterinos y el preservativo, en ese orden están presentes en el texto. Los tres primeros involucran una acción a realizar por las mujeres, el primero implica la utilización, en cualquiera de sus presentaciones (ingesta, parches o inyecciones) de hormonas para controlar la ovulación, los espermicidas se colocan en la vagina de la mujer y por último se presenta la utilización de un dispositivo que se coloca en el útero. También en este apartado se presenta el uso de la píldora del día después y se informa que puede ser utilizada por las mujeres después de una relación en la que hayan faltado o fallado los métodos anticonceptivos, pero que su uso no puede ser regular y debe estar controlado por un profesional especializado: ginecólogo o endocrinólogo aquí nuevamente y desde la letra escrita que se presenta a varones como profesionales a los que debe consultarse.

En cuarto lugar, se informa sobre la utilización del preservativo masculino, nuevamente aparecen errores de redacción, en tal caso debería decir que este dispositivo está desarrollado para ser utilizado por los varones. También, con errores de redacción, se presenta el preservativo femenino, donde debería decir usado por mujeres

Como último punto, antes de las actividades que caracterizan el final de todos los capítulos de este libro se incluye el tema de la interrupción del embarazo: el aborto ${ }^{\mathrm{vii}}$, en este 


\section{ANÁLISIS DE TEXTOS DE LA ASIGNATURA SALUD Y ADOLESCENCIA DE LA ESCUELA SECUNDARIA. ¿ESI DÓNDE ESTÁS QUE NO TE PUEDO ENCONTRAR?}

apartado nuevamente toma protagonismo la imagen que acompaña el texto, donde se ven dos personas adultas, una mujer y un hombre, alrededor de una mesa junto a una joven adolescente que se la ve claramente apesadumbrada. El epígrafe dice: la información, la comprensión y el cariño son fundamentales para evitar pasar por situaciones tan dolorosas, la imagen muestra una joven como si la mujer fuera la única que debe informarse.

\section{CONCLUSIONES. Líneas para seguir pensando}

La ley N 26150 de Educación Sexual Integral, a nivel nacional, contempla el tratamiento del tema en las escuelas, pero esto no basta para hacer circular la palabra al interior del cuerpo docente y del espacio escolar. Los argumentos que esgrime el profesorado son variados, por un lado manifiestan que la perspectiva de género no es un tema de su área de incumbencia, considerando a la escuela como meramente instructiva, y por el otro no se considera preparado para abordar dicha temática con solvencia.

No son muchos los profesores y las profesoras que entienden a la formación escolar como una etapa donde niños, niñas y jóvenes forman y transforman subjetividades.

Los miembros del cuerpo docente, que a diario habita las escuelas secundarias, se resisten a trabajar con temas de género dado que en muchos casos tiene que vencer sus propios prejuicios y no están dispuestos a hacerlo. En otros casos enarbolan las banderas de la educación sexual integral y, desconociendo el tema, sólo se orientan a la sexualidad genital activa, reproduciendo estereotipos de género que muchas veces, en el mejor de los casos, el propio estudiantado pone en tela de juicio y confronta. La adolescencia demanda y necesita otra formación. Se necesitan docentes dispuestos a deconstruir y romper sus propias estructuras de pensamiento y reconstruirlo y reaprender nuevas formas, y al parecer no es tarea sencilla.

Por más que existan leyes que contemplen estas temáticas, la realidad nos lleva a concluir que con la sola información no alcanza para resolver problemáticas sociales.

El sistema educativo responde a pujas de poder que se (re)configuran asumiendo diferentes formas en relación al contexto social en el que se halla inmerso. Este sistema social es el que, en diferentes momentos, asume una determinada forma de concebir lo femenino y lo masculino reproduciendo la matriz binaria heteronormativa normal. Si bien, amparados en leyes como la de identidad de género y de matrimonio igualitario, muchos colectivos minoritarios 


\section{ANÁLISIS DE TEXTOS DE LA ASIGNATURA SALUD Y ADOLESCENCIA DE LA ESCUELA SECUNDARIA. ¿ESI DÓNDE ESTÁS QUE NO TE PUEDO ENCONTRAR?}

luchan por visibilizarse y romper las estructuras de la heteronormatividad, el camino que queda por recorrer es largo y plagado de obstáculos.

Por lo tanto, todo lo que queda por fuera de la norma es considerado anormal y eso justifica y avala que sea rechazado, eliminado, silenciado, invisibilizado, escondido. Fuera de esta categorización de la normalidad quedan otras identidades posibles a las que no se les dedica ni siquiera un pequeño párrafo en las páginas de los libros escolares: gays, lesbianas, travestis, transexuales, transgéneros, intersexuales y otras que van emergiendo de la oscuridad y que, lamentablemente, pareciera que deberán esperar para ser incluidos en este sistema escolar que proclama a los cuatro vientos su poder inclusor meramente discursivo.

una sociedad desigual produce instituciones que tienden a reproducir la desigualdad y, es responsabilidad de la institución escolar y del mundo adulto en su conjunto encontrar los medios para que todxs ingresen, permanezcan y culminen la educación obligatoria con niveles de calidad equivalentes". (MORGADE, 2016, p.24)

Si los textos escolares no son interpelados por docentes que reflexionen, e interpreten los conceptos y sólo se remitan a ofrecerlos como material de estudio a su alumnado, la escuela continuará con la reproducción de estereotipos anquilosados sin siquiera notar que ofrece al alumnado cautivo en las escuelas, el germen para continuar con las desigualdades sociales que enfrentan a los seres humanos.

\section{REFERENCIAS}

AGUADO TERRÓN, J. M. Introducción a las teorías de la información y la comunicación. Universidad de Murcia, 2004.

BONDER, G. Género y Subjetividad. Avatares de una relación no evidente. Encuentro de Universidades de Latinoamérica y el Caribe: Género y epistemología: mujeres y disciplinas. Montecino, S y Obach, A, (comp.) Universidad de Chile. Lom Ediciones, pp. 29-55. España, 1999.

BOURDIEU, P. Las estrategias de la reproducción social. Buenos Aires: Siglo XXI Editores, 2011.

BUTLER, J. Lenguaje, poder e identidad. Madrid: Editorial Síntesis, 1997.

Deshacer el género. Barcelona: Paidos, 2006.

Dar cuenta de sí mismo. Violencia ética y responsabilidad. Buenos Aires: Amorrrortu Ediciones, 2012 .

Revista RBBA $\mid$ Revista Binacional Brasil Argentina 
ANÁLISIS DE TEXTOS DE LA ASIGNATURA SALUD Y ADOLESCENCIA DE LA ESCUELA SECUNDARIA. ¿ESI DÓNDE ESTÁS QUE NO TE PUEDO ENCONTRAR?

Cuerpo que importan. Sobre los límites materiales y discursivos del sexo. Buenos Aires: Paidós, 2012b.

DEUTSCH, M. y Krauss, R. En Teoría en psicología social. Buenos Aires: Paidós, 1969.

FOUCAULT, M. Historia de la Sexualidad. Buenos Aires: Siglo XXI Editores, 2012.

GIDDENS, A. Consecuencias de la modernidad. Madrid: Alianza Editorial, 1994.

LAUDANO, C. Género te habíamos amado tanto. Cuadernos FHyCS-UNju, No 31 pp 147 a 160. Argentina, 2006.

MARTIN CASARES, A. Antropología de Género. Cultura, Mitos y Estereotipos Sexuales. España: Universidad de Valencia, 2006.

MC MILLAN, J. y Schumacher, S. Investigación Educativa. Madrid: Pearson Addison Wesley Editores, 2005.

MORGADE, G. Educación Sexual Integral con perspectiva de género. La lupa de la ESI en el aula. Buenos Aires: Homo Sapiens Ediciones, 2016.

Aprender a ser varón. Aprender a ser mujer. Buenos Aires: Ediciones Novedades Educativas, 2001.

Toda educación es sexual. CABA, Argentina: La Crujía Ediciones, 2011.

MOSCOVICI, S. El psicoanálisis, su imagen y su público. Huemul. Buenos Aires. Argentina. (1961). https://taniars.files.wordpress.com/2008/02/moscovici-el-psicoanalisis-su-imagen-ysu-publico.pdf Consultado el 15/8/2019.

NARODOWSKI, M. y Manolakis, L. "Estado, mercado y textos escolares. Notas históricas para un modelo teórico". En: Revista Educación y Pedagogía. Medellín: Facultad de Educación. Vol. XIII, No. 29-30, pp. 27-38, 2001.

PASSERON, J. C. La teoría de la reproducción social como teoría del cambio: una evaluación crítica del concepto de "contradicción interna". (1983) http://codex.colmex.mx:8991/exlibris/aleph/a18_1/apache_media/R9JPK3PG7ANSSTY4MU IQ3G5K887HSM.pdf Consultado el 22/2/2019.

PÉREZ GÓMEZ, A., “Comprender la enseñanza en la escuela. Modelos metodológicos de investigación educativa”, en Gimeno Sacristán, J. y Pérez Gómez, Comprender y transformar la enseñanza. Madrid: Morata, 1994.

UNESCO Educación Integral de la Sexualidad: Conceptos, Enfoques y Competencias. (2014) http://unesdoc.unesco.org/images/0023/002328/232800S.pdf_Consultado el 26/1/2020. 
ANÁLISIS DE TEXTOS DE LA ASIGNATURA SALUD Y ADOLESCENCIA DE LA ESCUELA SECUNDARIA. ¿ESI DÓNDE ESTÁS QUE NO TE PUEDO ENCONTRAR?

\section{LEYES, RESOLUCIONES Y DISEÑOS CURRICULARES}

- Ley 1420 de Educación Común (1884) www.bnm.me.gov.ar/giga1/normas/5421.pdf Consultado el 15/6/2020.

- Ley 26150 Programa Nacional de Educación Sexual Integral http://servicios.infoleg.gob.ar/infolegInternet/anexos/120000-124999/121222/norma. htm Consultado el 15/6/2020.

- Ley 14744 ESI de la Provincia de Buenos Aires http://www.notivida.com.ar/legprovincial/Pcia\%20BsAs,Ley14744,ESI.html Consultado el 15/6/2020.

- Diseño curricular Salud y Adolescencia http://servicios.abc.gov.ar/lainstitucion/organismos/consejogeneral/disenioscurriculare s/secundaria/materias_comunes_a_todas_las_orientaciones_de_4anio/salud_y_adolesc encia_4.pdf Consultado el 15/6/2020.

\section{SOBRE LAS AUTORAS}

Claudia Arango es Doctora en Educación por la Universidad Nacional de Quilmes (UNQ) Argentina, Investigadora Independiente de la UNQ y miembro del Grupo de Investigación en Enseñanza de las Ciencias (GIECien).

Dirección eléctrónica: cbarango@gmail.com

ORCID: 0000-0003-1785-8559

Silvia Porro es Doctora en Ciencias Bioquímicas por la Universidad Nacional de La Plata (UNLP), Argentina. Profesora Honoraria de la Universidad Nacional de Quilmes (UNQ) y Directora del Grupo de Investigación en Enseñanza de las Ciencias (GIECien) de la UNQ.

Dirección electrónica: sporro@unq.edu.ar

ORCID: 0000-0003-3515-1856

Recebido em: 02/05/2020

Aprovado em: 10/06/2020

Publicado em: 01/07/2020

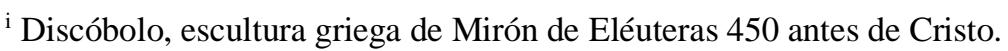

ii Los términos que figuran entre paréntesis fueron incluidos por la autora de este trabajo.

iii SEGATO, R. Entrevista realizada por radio Gen107,4. (2017). Disponible en: http://genfm.com.ar/2017/06/04/rita-segato-las-mujeres-tenemos-que-probarnos-como-sujetos-morales-todoslos-dias/ Consultado en 28 de octubre de 2018.

iv Idem.

${ }^{\mathrm{v}}$ La negrita es propia del texto original que se está analizando.

${ }^{v i}$ Se recuerda que esta categoría pertenece a las autoras de este trabajo y es útil a los fines del análisis del material bibliográfico.

${ }^{\text {vii }}$ Se recuerda que el libro en análisis fue impreso en 2012 y el presente trabajo se termina de escribir luego de que se tratara y fuera rechazada la ley por el derecho al aborto legal y gratuito en hospitales públicos, por ambas cámaras, en 2018.

Revista RBBA Revista Binacional Brasil Argentina 